\title{
Effects of aclidinium on determinants of COPD severity: symptoms and quality of life
}

\author{
This article was published in the following Dove Press journal: \\ International Journal of COPD \\ 5 December 2016 \\ Number of times this article has been viewed
}

\section{Marco Contoli ${ }^{1}$ \\ Paolo Solidoro ${ }^{2}$ \\ Fabiano Di Marco 3,4 \\ Nicola Scichilone ${ }^{5}$ \\ Angelo Corsico 6 \\ Fulvio Braido ${ }^{7}$ \\ Pierachille Santus 4,8}

'Research Centre on Asthma and COPD, Department of Medical Sciences, University of Ferrara, Ferrara, Italy; ${ }^{2}$ Cardiovascular and Thoracic Department, Città della Salute, Turin, Italy; ${ }^{3}$ Department of Health Sciences, University of Milan, Milan, Italy; ${ }^{4}$ Respiratory Unit, San Paolo Hospital, Milan, Italy; ${ }^{5}$ Department of Internal Medicine, Section of Pulmonology (DIBIMIS), University of Palermo, Palermo, Italy; ${ }^{6}$ Department of Molecular Medicine, Fondazione IRCCS Policlinico San Matteo, Pavia, Italy; ${ }^{7}$ Allergy and Respiratory Diseases Clinic, DIMI, University of Genoa, IRCS AOU San Martino-IST, Genoa, Italy; ${ }^{8}$ Pulmonary Rehabilitation Unit, Fondazione Salvatore Maugeri, Scientific Institute of Milan-IRCCS, Milan, Italy
Correspondence: Pierachille Santus UOC Pneumologia, Ospedale L. Sacco, Via G.B Grassi, 74, 20157 Milan, Italy Tel +39023904340I

Fax +390239042372

Email pierachille.santus@unimi.it

\begin{abstract}
The pathophysiology of chronic obstructive pulmonary disease (COPD) includes persistent airflow limitation, altered gas exchange, and enhanced chronic inflammatory response. According to disease severity in individual patients, exacerbations and comorbidities frequently occur. The overall nocturnal and daily symptoms have a strong impact on patient quality of life and clinical outcomes. Bronchodilators, by targeting two important aspects of COPD pathophysiology, ie, bronchoconstriction and lung hyperinflation, are the mainstay of therapy for COPD. Aclidinium bromide in particular is an anticholinergic molecule, approved for maintenance bronchodilator treatment of stable COPD, that combines high antimuscarinic activity with strong kinetic selectivity for the M3 receptor subtype. Moreover, the elevated plasma clearance of aclidinium has been related to low systemic bioavailability and low incidence of anticholinergic adverse events, whereas the reduced residence time at M2 receptors provides good cardiovascular safety. Altogether, these characteristics result in a high safety and tolerability profile. This review aims to reappraise the contribution of symptoms and of the level of quality of life determinants on COPD severity and to evaluate how therapeutic strategies with aclidinium may positively impact on these specific determinants of disease severity.
\end{abstract}

Keywords: COPD, quality of life, daily symptoms, LAMA, aclidinium

\section{Introduction}

Chronic obstructive pulmonary disease (COPD) is a common preventable and treatable disease, characterized by persistent airflow limitation that is not fully reversible and usually progressive. COPD may often be associated with extrapulmonary concomitant conditions, including cardiovascular and metabolic disease. The natural history of the disease is punctuated by recurrent episodes of worsening in symptoms and lung function termed "exacerbations". Comorbidities and exacerbations contribute to the overall severity in individual patients. COPD is, among chronic conditions, one of the principal causes of years lived with disability and mortality. ${ }^{1}$

According to the Global Initiative for Chronic Obstructive Lung Disease (GOLD) international guidelines, respiratory symptoms and the impact of symptoms on quality of life (QoL) are important determinants of the disease severity and of the treatment strategy. ${ }^{2}$

Long-acting muscarinic antagonists (LAMAs) are key to performing maintenance treatments in COPD patients. Aclidinium bromide was approved by the European Medicines Agency and the US Food and Drug Administration in 2012 for maintenance bronchodilator treatment in stable adult patients with COPD. ${ }^{3}$ Aclidinium has high affinity for all five muscarinic receptors and a lower potential for anticholinergic adverse events. ${ }^{4}$ 
This review aims to reappraise the contribution of symptoms and of the level of QoL determinants on COPD severity and to evaluate how therapeutic strategies with the LAMA aclidinium may positively impact on these specific determinants of disease severity.

\section{Determinants of COPD severity: focus on symptoms and QoL Symptoms in COPD}

Cough, dyspnea, and sputum production are hallmarks of respiratory symptoms in COPD and may occur many years before airflow limitation. These symptoms occur across all levels of disease severity and show very weak correlations between the severity of lung function obstruction and the magnitude of symptomatology. A noninterventional multicenter study, designed to better characterize COPD phenotypes in a large cohort of COPD patients, showed that airflow limitation measured as forced expiratory volume in 1 second reduction does not capture the heterogeneity of the disease. ${ }^{5}$

Indeed, airflow limitation was poorly, albeit significantly, associated with breathlessness. Moreover, there was a considerable overlap between GOLD stages, with up to $40 \%$ of mild COPD patients experiencing moderate-to-severe dyspnea and up to approximately $25 \%$ of COPD patients with very severe airflow obstruction experiencing very mild or no dyspnea. ${ }^{5}$ These data clearly indicate that lung function measurement (which is essential for diagnosis and evaluation of a COPD patient) cannot be regarded as a surrogate of symptom severity and that the symptoms (and in particular dyspnea) must be specifically evaluated. The presence and persistence of chronic symptoms negatively impact the clinical manifestation of COPD, irrespective of the severity of airflow limitation, and patients with symptomatic COPD (in particular with dyspnea) exhibit poorer long-term prognosis/ survival compared with asymptomatic patients. ${ }^{6}$

Several concomitant conditions can contribute to dyspnea in a COPD patient, including chronic heart failure, anemia, cachexia, malnutrition, etc. In this regard, one can speculate that the presence of dyspnea can reflect not only the severity of the airflow obstruction but also more generally the severity of a COPD patient. The GOLD international guidelines propose the Modified British Medical Research Council (mMRC) Dyspnea Scale as a simple grading system to assess a patient's level of dyspnea/shortness of breath. ${ }^{7}$ Indeed, the mMRC correlates well with other measures of health status and predicts future mortality risk. The scale scores the dyspnea based on physical activity limitations ranging from 0 "I only get breathless with strenuous exercise" to 4 "I am too breathless to leave the house or I am breathless when dressing". Despite mMRC being a simple and quick tool that can be used in daily clinical activity, its main limitation is an inability to provide a comprehensive assessment of the multiple symptomatic effects of COPD. ${ }^{8}$

\section{Symptom heterogeneity and variability in COPD}

Chronic and daily variable symptoms are characteristics of the clinical manifestation of the disease. An observational multicenter European study evaluated the perception by COPD patients of respiratory symptoms over the day, the week, and the seasons. This study determined that more than $60 \%$ of patients with severe COPD reported respiratory symptoms with a worse perception in the morning. ${ }^{9}$ An internet-based questionnaire survey on more than $800 \mathrm{COPD}$ patients from Europe and the USA, including 289 patients with severe COPD, also addressed the perception of COPD symptoms at different times in the day and night, assessing their impact on morning activities and on the daily routine of the patients. The study confirmed morning as the worst time of the day in $46 \%$ patients with severe COPD. Interestingly, nighttime was the second most difficult time of the day, as reported by $34 \%$ of severe COPD patients. ${ }^{10}$ Other more recent epidemiological data indicate that nocturnal symptoms and related sleep disturbances have a much higher prevalence, correlated with disease severity and exceeding 75\% among patients with most severe COPD. ${ }^{11}$

To further evaluate the characteristics of nighttime symptoms in COPD, a prospective study assessed the polysomnographic and arterial oxygen saturation profiles along with other sleep parameters in a cohort of COPD patients with stable mild-to-moderate COPD, compared with matched controls with no airflow obstruction. The results of this study revealed that patients with COPD had an overall lower sleep efficiency, a lower total sleep time, and lower mean overnight oxygen saturation. Moreover, these patients were significantly more likely to be reporting insomnia and difficulty in initiating and maintaining sleep, resulting in an increased score of overall psychiatric sleep disorders. ${ }^{12}$

Several causes and mechanisms have been claimed to explain the increased symptomatology of COPD patients during nighttime/sleep time, including age and obesity, therapy with certain drugs, disease-specific symptoms (ie, wheezing and cough), or comorbidities related to sleep disorders, including COPD-dependent psychological distress. ${ }^{13}$ Specific functional alterations occurring at nighttime can be responsible for altered respiratory symptomatology. In 
particular, a study on nocturnal oxyhemoglobin desaturation has shown that the supine position impaired the functional residual capacity in COPD patients, with consequent increase of pulmonary hyperinflation. ${ }^{14}$ On the other hand, hypoxemia caused by altered lung function in COPD has been associated with interference with normal sleep architecture. ${ }^{15}$

The long-term consequences of nocturnal symptoms and altered sleep structure may have a severe impact on the outcome of COPD patients, because altered lung functions, onset or aggravation of cardiovascular comorbidities, increase of the frequency of exacerbations, and mental disturbances generally impair QoL and may finally increase the risk of death ${ }^{13}$ (Figure 1). In this regard, a retrospective study examined nocturnal hyperinflation, one of the most common COPD symptoms associated with reduced sleep efficiency. Both polysomnography data and

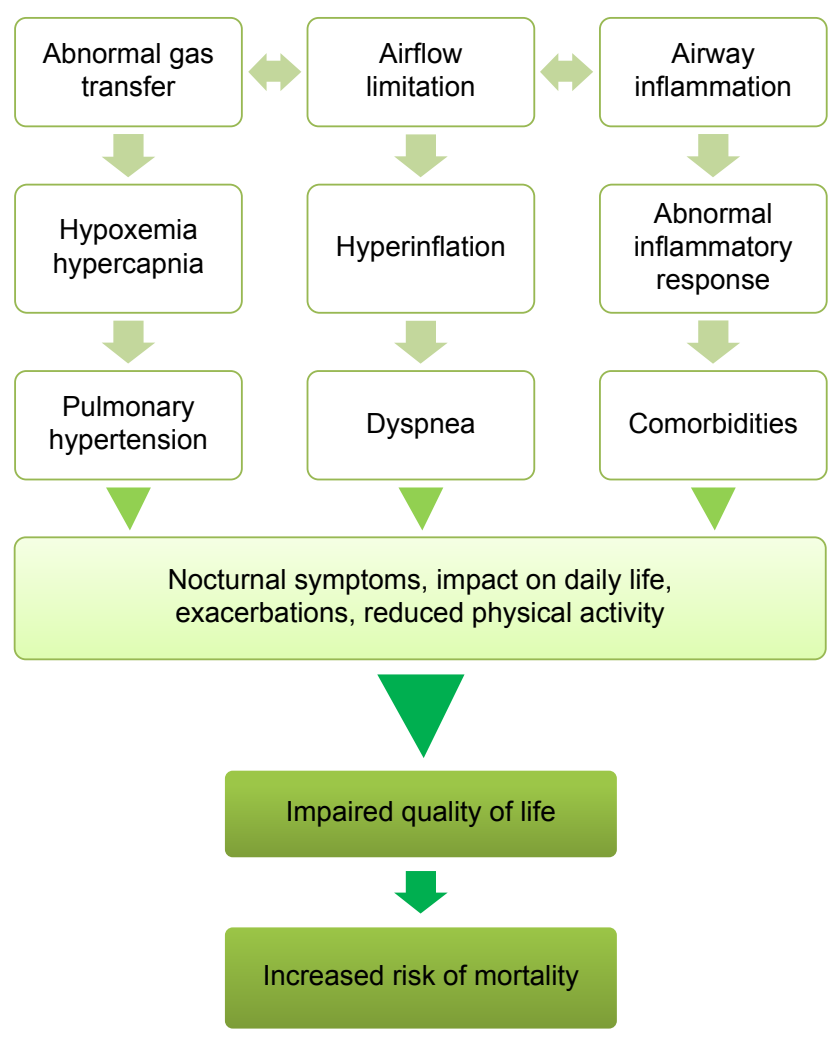

Figure I Diagrammatic representation of the different features of COPD and of their mutual relationships, converging toward impairment of QoL and increased risk of mortality.

Notes: The decline in lung function, accompanied by airflow limitation, causing hyperinflation and dyspnea, is correlated with the extent of airway inflammation and contributes to parenchymal damage, which causes abnormal gas transfer with the consequent hypoxemia and hypercapnia, leading to pulmonary hypertension. The abnormal inflammatory response to noxious particles and gases is dependent on airway chronic inflammation and correlates with several comorbidities. These alterations are at the basis of nocturnal and whole-day symptoms and of reduced physical activity. All symptoms and limitations determine a poor QoL that is associated with an enhanced mortality risk.

Abbreviation: QoL, quality of life. pulmonary function tests were performed, revealing a statistically significant association between increased severity of lung hyperinflation and worse sleep efficiency. ${ }^{16}$ Indeed, not only are nighttime/sleep time symptoms frequently present in COPD, but also even more importantly they are clinically relevant. An interesting epidemiological study revealed that the prevalence of nighttime symptoms, in particular dyspnea, is a significant predictor of poor prognosis in COPD, being associated with increased exacerbation rate and shorter survival. ${ }^{17}$ These data suggest that targeting the worsening of nighttime symptoms can be of clinical relevance in COPD patients. Nevertheless, nocturnal symptoms are often underestimated by physicians, while patients with COPD suffering nighttime symptoms do not always report these symptoms and the related sleep disturbances. ${ }^{13}$

Altogether, these data identify nighttime dyspnea and, more generally, chronic dyspnea as a valuable predictor of poor prognosis in COPD patients. ${ }^{17}$ According to the GOLD guidelines, the level of these symptoms (and in particular of dyspnea) contributes to the assessment of disease severity. ${ }^{8}$ Moreover, monitoring of these symptoms guides the clinician in determining when the therapy needs to be modified and in identifying a relevant target for intervention.

\section{QoL in COPD}

QoL measures a complex array of patient-reported outcomes, including physical, psychological, and social components, which have particular relevance in a chronic disease like COPD. These range from symptoms (cough, sputum production, shortness of breath or dyspnea, and wheezing attacks) to interference with daily work and social activity, even causing a nuisance with family or friends and embarrassment in public.

The importance of measuring QoL relies not only on its ability to identify COPD features causing problems to the patients but also in a greater ability to discriminate among different levels of severity stages of COPD and to correlate with clinical measures of COPD more effectively than generic measures of health. ${ }^{18}$ It has been demonstrated that QoL has a strong impact on the long-term prognosis of COPD patients. ${ }^{17}$ Moreover, a study on more than 300 patients showed that QoL was an independent risk factor for mortality in COPD. ${ }^{19}$ Similar to symptoms, QoL also correlates weakly with lung function. A cohort of COPD patients from primary care settings across seven countries in Europe was the subject of a cross-sectional, observational study on QoL, investigated by means of disease-specific and generic questionnaires. The results revealed that even patients with mild and moderate 
COPD experience high levels of respiratory symptoms and physical impairment. ${ }^{20}$ Similarly, the ECLIPSE cohort study showed that COPD patients with mild airflow obstruction can exhibit poor QoL. ${ }^{5}$ Therefore, impaired lung function cannot be considered a surrogate for poor QoL, which must be specifically measured in COPD patients.

The disease-specific St George Respiratory Questionnaire $\left(\right.$ SGRQ) ${ }^{21}$ allows the assessment of how disease activity impacts on a number of aspects of patient QoL and is widely accepted as a support of lung function measurements for the diagnosis of COPD. ${ }^{22}$ SGRQ is a self-administered questionnaire that was designed to measure the respiratory QoL and includes 50 items in three components: symptoms, activity, and impact on daily life. The scores range from 0 to 100 (0 indicating no impairment in the QoL) and higher SGRQ scores represent worse QoL, with a score of 100 being the worst possible. The COPD Assessment Test was developed as a short, simple, unidimensional questionnaire based on eight items measuring the impairment of health status in COPD. The score system ranges from 0 to 40 , closely correlated to that of SGRQ. The COPD Assessment Test is available as validated translations in 58 different languages, making it applicable worldwide..$^{23}$

\section{Effects of symptoms on QoL}

Several aspects can affect QoL. In particular, it has been shown that the presence of symptoms is an important determinant of poor QoL in COPD patients. A recent observational study conducted in 85 clinical practice centers of eight European countries evaluated the symptom profile of more than 700 patients with COPD throughout the whole 24-hour day. Interestingly, the study showed a significant relationship between nighttime, early morning, and daytime symptoms, and that the presence of symptoms (in each period) was associated with worse patient-reported outcomes, including poor QoL. ${ }^{24}$ Likewise, a large study performed on more than 2,800 patients from five European countries revealed that patients with nighttime symptoms scored a significantly lower QoL compared with patients without nocturnal symptoms. ${ }^{11}$ Overall, these data pointed to the interdependence between worsening of symptoms and decline of QoL. The relief of chronic symptoms is part of the effective management of COPD with the goal of improving the QoL of patients. Long-term treatment with long-acting bronchodilators was successful in achieving these goals in COPD. ${ }^{25}$

\section{Bronchodilator therapy}

Bronchoconstriction and lung hyperinflation are important determinants of the symptoms related to COPD.
The evidence elucidating the importance not only of bronchodilation but also of pulmonary desufflation are strong and crucial for a better understanding of the effect of bronchodilators on respiratory clinical parameters such as dyspnea. ${ }^{26,27}$

A LAMA, alone or in combination with a long-acting $\beta 2$-adrenergic agonist (LABA) and inhaled corticosteroids, is the most commonly used agents in the treatment of COPD. These combination treatments are recommended by the GOLD for the management of COPD patients as single agents (LAMA or LABA) or in combination, according to the stage of the disease, the patient response, and the risk of exacerbations. ${ }^{8}$ Long-acting bronchodilators have been established as standard treatment for COPD patients. The formulation of these agents, designed to be administered by inhalation, offers an optimized delivery to the targeted site and minimizes systemic bioavailability, thus reducing adverse effects. Aclidinium bromide, in particular, combines high selectivity for M3 muscarinic receptors, long duration of action, and rapid clearance in plasma. This long-acting inhaled bronchodilator is effective in reducing exacerbations and related hospitalizations and in improving symptoms and health status in COPD. ${ }^{28-31}$

\section{Inhaled aclidinium bromide}

Aclidinium bromide, containing a quaternized (3R)-quinuclidinol ester, with the chemical formula 3R-(2-hydroxy2,2-dithiophen-2-yl-acetoxy)-1-(3-phenoxy-propyl)-1azonia-bicyclo[2.2.2] octane bromide, is an inhaled LAMA which, as noted previously, was approved by the US Food and Drug Administration and the European Medicines Agency in 2012 for use in moderate-to-severe stable COPD patients. According to all preliminary clinical and registration studies, aclidinium bromide is generally well tolerated in patients with COPD, with a low incidence of antimuscarinic (anticholinergic) adverse effects and with safety profiles similar to placebo. ${ }^{28,29}$ Several adverse effects, such as tachycardia and digestive tract disturbances, have been associated with the administration of muscarinic antagonists, and many efforts have been made to design formulations with reduced bioavailability. Aclidinium bromide, in contrast to tiotropium and ipratropium, displays an increased plasma clearance, with a lower potential for systemic adverse events. Moreover, aclidinium bromide has a long residence half-life at M3 receptors (located on airway smooth muscle) and a reduced residence half-life at M2 receptors (mainly located in the heart), resulting in selective antagonism to the M3 receptors. ${ }^{4}$ A recent randomized, double-blind, crossover study demonstrated that even in severe and very severe 


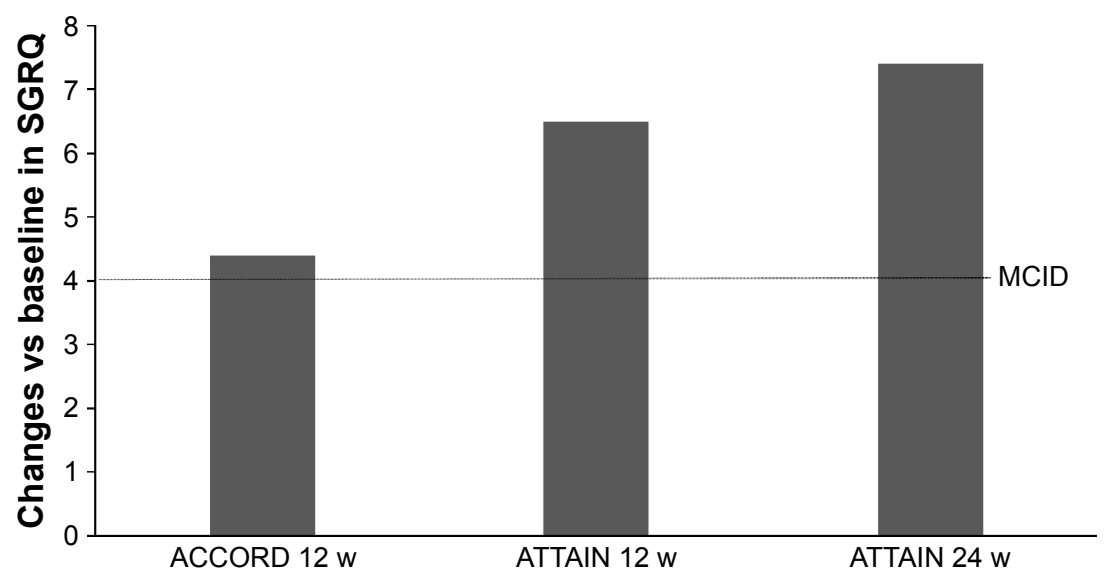

Figure 2 Changes from baseline SGRQ total score of ACCORD study ${ }^{29}$ and ATTAIN study. ${ }^{28}$

Notes: The results of ATTAIN study are related to the evaluation after 12 and 24 weeks of therapy. Data are reported as mean values.

Abbreviations: SGRQ, St George Respiratory Questionnaire; w, week; MCID, minimal clinically important difference.

COPD patients, a rapid and important desufflation, along with the improvement in lung ventilation inhomogeneity, is promoted by aclidinium. ${ }^{32}$ These results are of particular relevance in view of the main pathophysiological role played by hyperinflation and airflow limitation in inducing dyspnea and reducing QoL in patients with COPD.

Since inhalation is the optimal route of administration of bronchodilators, the inhaler device is as relevant as the $\operatorname{drug}(\mathrm{s})$ in the management of COPD. ${ }^{33}$ As recommended by the consensus statement of the European Respiratory Society (ERS), the choice of the aerosol delivery device should be based on the patient's ability, inspiratory flow levels, and other clinical conditions. ${ }^{34}$ A recent survey on a representative sample of the Italian elderly patient population showed that the large majority of these patients considered the multidose breath-actuated dry powder inhaler device, Genuair ${ }^{\circledR}$, well accepted and easy to use, irrespective of the presence of age-related difficulties. ${ }^{35}$

\section{Effects of aclidinium on symptoms and QoL}

Two Phase III studies, the ATTAIN 24-week, doubleblind trial (NCT01001494) on more than 800 patients and the ACCORD-I 12-week, double-blind, multicenter trial (NCT00891462) on more than 500 patients, assessed the efficacy of 6 weeks treatment with aclidinium bromide versus placebo in patients with $\mathrm{COPD}^{28,29}$ (Figures 2 and 3). The results of both trials showed that inhaled aclidinium bromide significantly improved bronchodilation, health status, and dyspnea versus placebo. ${ }^{28,29}$ The ACCORD-I study found a significant reduction in the frequency and severity of nocturnal symptoms compared with placebo at Week 12 in patients treated with both doses of aclidinium. ${ }^{29}$

Pharmacological trials on the comparison between LAMAs on relevant clinical outcomes of COPD are very important to help and support the treatment decision process of the physicians. A recent systematic review and network meta-analysis evaluated the comparative efficacy of LAMA

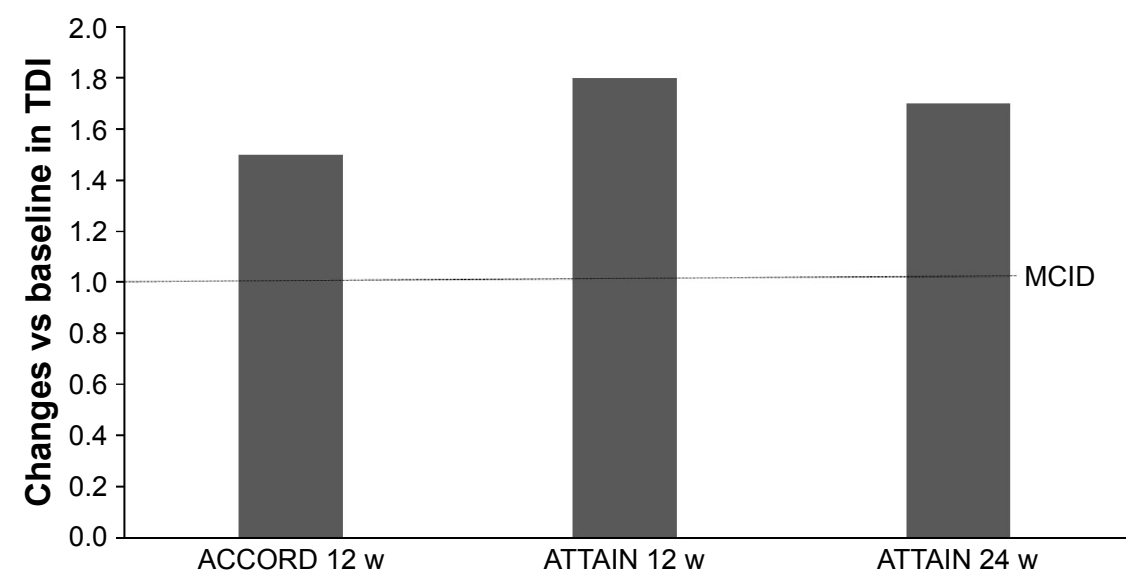

Figure 3 Changes from baseline TDI score of ACCORD study ${ }^{29}$ and ATTAIN study. ${ }^{28}$

Notes: The results of ATTAIN study are related to the evaluation after 12 and 24 weeks of therapy. Data are reported as mean values.

Abbreviations: TDI, transitional dyspnea index; w, week; MCID, minimal clinically important difference. 
monotherapies in COPD. ${ }^{36}$ While, two trials included a headto-head comparison between aclidinium and tiotropium in the study design. A Phase IIa randomized, double-blind, doubledummy, crossover trial (NCT00868231) compared inhaled aclidinium bromide $400 \mu \mathrm{g}$ bid (twice daily) with tiotropium $18 \mu \mathrm{g}$ qd (once daily) and with placebo for 15 days, with a 9- to 15-day washout between treatment periods. Results derived from symptoms diaries revealed significant improvements from baseline in nighttime symptoms with bid aclidinium versus placebo, which were not observed with daily tiotropium. ${ }^{37}$ Reductions in COPD symptom score were consistently greater with aclidinium than with tiotropium, but these differences did not reach statistical significance. ${ }^{37}$

A randomized, double-blind, Phase IIIb study (NCT01462929) compared the bronchodilation efficacy of aclidinium bromide vs tiotropium and vs placebo over a period of 24 hours in patients with moderate-to-severe COPD. ${ }^{37}$ Pulmonary function and symptoms were examined in more than 400 patients. The results indicated that aclidinium $400 \mu \mathrm{g}$ bid ensured a 24-hour effective bronchodilation and provided a significant improvement of early morning activities and greater improvement of COPD symptoms, compared with tiotropium. ${ }^{38}$

Other LAMAs are available for long-term inhaled treatment of COPD, including glycopyrronium and umeclidinium. A significant improvement in $\mathrm{QoL}$ and symptom scores compared with placebo have been shown also for glycopyrronium ${ }^{39}$ and umeclidinium, ${ }^{40}$ but no direct comparison with aclidinium is available. Thus, any conclusion on the relative effectiveness of these molecules on the tested clinical outcomes can be biased by methodological study concerns including different severity of the patients recruited, different sample size, and different duration of the studies and outcomes.

A relevant point in evaluating aclidinium therapy is that the improvement in clinical outcomes (symptom control and improvement of $\mathrm{QoL}$ ) is spread from moderate-to-severe COPD patients, with remarkably low rates and severity of adverse events (Table 1).

\section{Conclusion}

In COPD patients, the presence of chronic respiratory symptoms is a key determinant of the severity of the disease. The symptoms associated with COPD, beyond affecting functional capacity and physical activity of the patients, have a strong impact on QoL, which in turn is also a determinant of COPD severity. ${ }^{9}$ Even more importantly, the presence/persistence of respiratory symptoms resulted in a

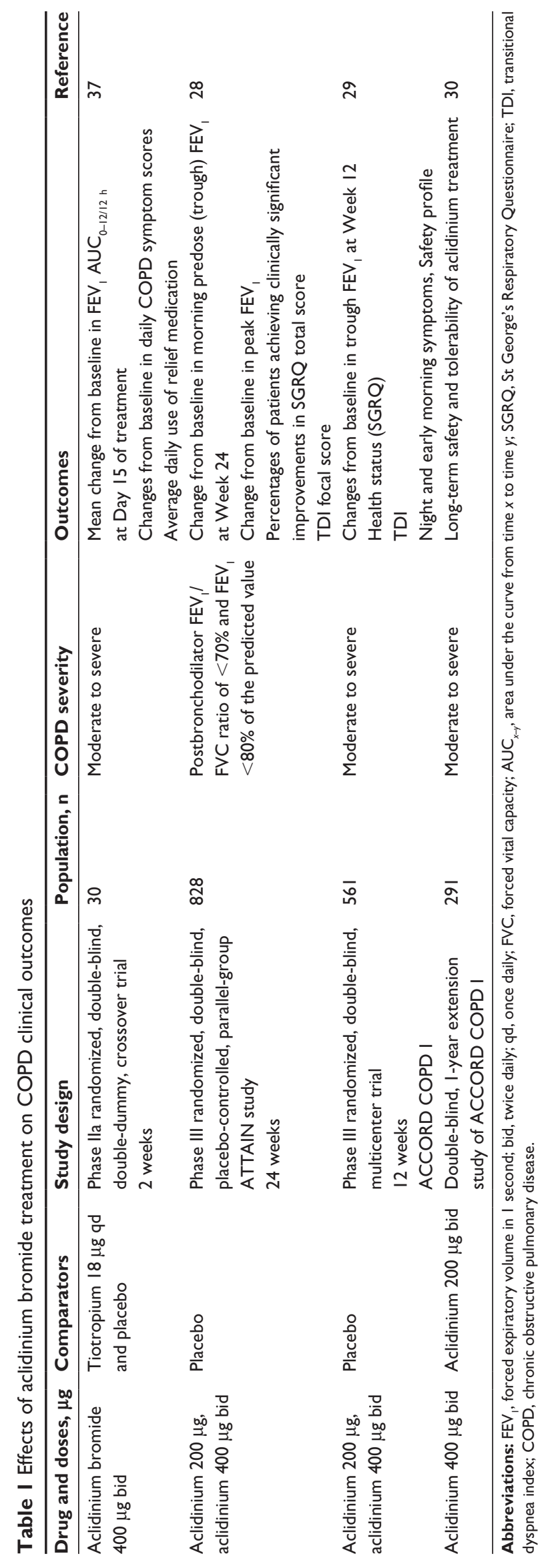


significantly increased risk of long-term mortality during the follow-up period of 11 years in a prospective study on the large Atherosclerosis Risk in Communities cohort in USA. ${ }^{41}$ In particular, severe dyspnea in COPD patients was identified as a risk factor for mortality, which normalized upon remission of the symptom, by a large longitudinal Dutch study with a follow-up of over 40 years. ${ }^{42}$

Staging of COPD severity based on pulmonary functions is strongly correlated with clinical outcomes of COPD. However, measures of QoL are able to capture more broad aspects and complementary information to lung function data in assessing disease status and outcome. ${ }^{18}$ Indeed, QoL was found to be significantly impaired in COPD patients across all severity grades, even in those with milder disease, with little difference between GOLD stages and wide variation within each GOLD stage. ${ }^{20}$

Moreover, symptoms and QoL should be considered independently in the assessment and monitoring of COPD patients in primary care. In particular, nighttime symptoms are of relevance because of the strong impact on daily activity, and also because of the prognostic value. ${ }^{17}$ Clinicians and general practitioners should not neglect nighttime symptoms during their clinical interviews and should consider this aspect as a specific target for therapy.

Long-acting bronchodilators (LABAs and LAMAs) are the mainstay of therapy for patients with moderate and severe COPD. Aclidinium bromide, with high antimuscarinic activity and a favorable safety profile, has demonstrated efficacy in controlling COPD symptoms over the 24-hour day period, including nocturnal symptoms, with a relevant impact on QoL and prognosis, irrespective of disease severity.,43 In conclusion, the favorable benefit-to-risk ratio in the clinical setting indicates that aclidinium has potential as a valuable treatment option for patients with COPD.

\section{Acknowledgments}

The authors thank Luisa Granziero, an independent medical writer, who provided medical writing support on behalf of Health Publishing \& Services Srl, Milan, Italy. They also thank Ray Hill, an independent medical writer, who provided native English editing and journal styling. This assistance was funded by AstraZeneca.

\section{Disclosure}

MC reports grants for research from Chiesi Farmaceutici and AstraZeneca, and personal fees for lectures and/or advisory boards from Chiesi Farmaceutici, AstraZeneca, Boehringer Ingelheim, Novartis, Menarini, Mundipharma, Almirall, and Zambon. NS has received financial support for research and for congress attendance from AstraZeneca, Boehringer Ingelheim, Chiesi Farmaceutici, Glaxo, SmithKline, Guidotti, Menarini, Novartis, and Zambon and has served as a consultant for AstraZeneca, Boehringer Ingelheim, Chiesi Farmaceutici, Mundipharma, Dompè, and Roche. FB has received financial support for research and for congress attendance from AstraZeneca, Boehringer Ingelheim, Chiesi Farmaceutici, Glaxo, SmithKline, Guidotti, Menarini, Novartis, and Zambon and has served as a consultant for AstraZeneca, Boehringer Ingelheim, Chiesi Farmaceutici, Mundipharma, and Dompè. P Santus reports research grants from Chiesi Farmaceutici, Pfizer, AirLiquide, and Almirall, and personal fees for lectures and/or advisory boards from Chiesi Farmaceutici, AstraZenexa, Boehringer Ingelheim, Novartis, Menarini, Malesci/Guidotti, Mundipharma, and Zambon. The authors report no other conflicts of interest in this work.

\section{References}

1. GBD Global Burden of Disease Study 2013 Collaborators. Global, regional, and national incidence, prevalence, and years lived with disability for 301 acute and chronic diseases and injuries in 188 countries, 1990-2013: a systematic analysis for the Global Burden of Disease Study 2013. Lancet. 2015;386(9995):743-800.

2. Vestbo J, Hurd SS, Agusti AG, et al. Global strategy for the diagnosis, management, and prevention of chronic obstructive pulmonary disease: GOLD executive summary. Am J Respir Crit Care Med. 2013;187(4): 347-365.

3. Gavalda A, Ramos I, Carcasona C, et al. The in vitro and in vivo profile of aclidinium bromide in comparison with glycopyrronium bromide. Pulm Pharmacol Ther. 2014;28(2):114-121.

4. Gavalda A, Miralpeix M, Ramos I, et al. Characterization of aclidinium bromide, a novel inhaled muscarinic antagonist, with long duration of action and a favorable pharmacological profile. J Pharmacol Exp Ther. 2009;331(2):740-751.

5. Agusti A, Calverley PM, Celli B, et al. Characterisation of COPD heterogeneity in the ECLIPSE cohort. Respir Res. 2010;11:122.

6. Lange P, Marott JL, Vestbo J, et al. Prediction of the clinical course of chronic obstructive pulmonary disease, using the new GOLD classification: a study of the general population. Am J Respir Crit Care Med. 2012; 186(10):975-981.

7. Bestall JC, Paul EA, Garrod R, Garnham R, Jones PW, Wedzicha JA. Usefulness of the Medical Research Council (MRC) dyspnoea scale as a measure of disability in patients with chronic obstructive pulmonary disease. Thorax. 1999;54(7):581-586.

8. GOLD Global Initiative for Chronic Obstructive Lung Disease. Global Strategy for the Diagnosis, Management, and Prevention of Chronic Obstructive Pulmonart Diesase (updated 2015), 2015. Available from: www.goldcopd.org/. Accessed August, 2015.

9. Kessler R, Partridge MR, Miravitlles M, et al. Symptom variability in patients with severe COPD: a pan-European cross-sectional study. Eur Respir J. 2011;37(2):264-272.

10. Partridge MR, Karlsson N, Small IR. Patient insight into the impact of chronic obstructive pulmonary disease in the morning: an internet survey. Curr Med Res Opin. 2009;25(8):2043-2048.

11. Price D, Small M, Milligan G, Higgins V, Gil EG, Estruch J. Impact of night-time symptoms in COPD: a real-world study in five European countries. Int J Chron Obstruct Pulmon Dis. 2013;8:595-603. 
12. Valipour A, Lavie P, Lothaller H, Mikulic I, Burghuber OC. Sleep profile and symptoms of sleep disorders in patients with stable mild to moderate chronic obstructive pulmonary disease. Sleep Med. 2011; 12(4):367-372.

13. Agusti A, Hedner J, Marin JM, Barbe F, Cazzola M, Rennard S. Nighttime symptoms: a forgotten dimension of COPD. Eur Respir Rev. 2011; 20(121):183-194.

14. Corda L, Novali M, Montemurro LT, et al. Predictors of nocturnal oxyhemoglobin desaturation in COPD. Respir Physiol Neurobiol. 2011; 179(2-3):192-197.

15. Owens RL, Malhotra A. Sleep-disordered breathing and COPD: the overlap syndrome. Respir Care. 2010;55(10):1333-1344; discussion 1344-1336.

16. Kwon JS, Wolfe LF, Lu BS, Kalhan R. Hyperinflation is associated with lower sleep efficiency in COPD with co-existent obstructive sleep apnea. COPD. 2009;6(6):441-445.

17. Lange P, Marott JL, Vestbo J, Nordestgaard BG. Prevalence of nighttime dyspnoea in COPD and its implications for prognosis. Eur Respir $J$. 2014;43(6):1590-1598.

18. Pickard AS, Yang Y, Lee TA. Comparison of health-related quality of life measures in chronic obstructive pulmonary disease. Health Qual Life Outcomes. 2011;9:26.

19. Domingo-Salvany A, Lamarca R, Ferrer M, et al. Health-related quality of life and mortality in male patients with chronic obstructive pulmonary disease. Am J Respir Crit Care Med. 2002;166(5):680-685.

20. Jones PW, Brusselle G, Dal Negro RW, et al. Health-related quality of life in patients by COPD severity within primary care in Europe. Respir Med. 2011;105(1):57-66.

21. Jones PW, Quirk FH, Baveystock CM, Littlejohns P. A self-complete measure of health status for chronic airflow limitation. The St George's Respiratory Questionnaire. Am Rev Respir Dis. 1992;145(6):1321-1327.

22. Weatherall M, Marsh S, Shirtcliffe P, Williams M, Travers J, Beasley R. Quality of life measured by the St George's Respiratory Questionnaire and spirometry. Eur Respir J. 2009;33(5):1025-1030.

23. Jones PW, Harding G, Berry P, Wiklund I, Chen WH, Kline Leidy N. Development and first validation of the COPD Assessment Test. Eur Respir J. 2009;34(3):648-654.

24. Miravitlles M, Worth H, Soler Cataluna JJ, et al. Observational study to characterise 24-hour COPD symptoms and their relationship with patient-reported outcomes: results from the ASSESS study. Respir Res. 2014; $15: 122$.

25. Rabe KF, Hurd S, Anzueto A, et al. Global strategy for the diagnosis, management, and prevention of chronic obstructive pulmonary disease: GOLD executive summary. Am J Respir Crit Care Med. 2007;176(6): 532-555.

26. Santus P, Radovanovic D, Henchi S, et al. Assessment of acute bronchodilator effects from specific airway resistance changes in stable COPD patients. Respir Physiol Neurobiol. 2014;197:36-45.

27. Santus P, Centanni S, Verga M, Di Marco F, Matera MG, Cazzola M. Comparison of the acute effect of tiotropium versus a combination therapy with single inhaler budesonide/formoterol on the degree of resting pulmonary hyperinflation. Respir Med. 2006;100(7):1277-1281.

28. Jones PW, Singh D, Bateman ED, et al. Efficacy and safety of twicedaily aclidinium bromide in COPD patients: the ATTAIN study. Eur Respir J. 2012;40(4):830-836.
29. Kerwin EM, D’Urzo AD, Gelb AF, Lakkis H, Garcia Gil E, Caracta CF. Efficacy and safety of a 12-week treatment with twice-daily aclidinium bromide in COPD patients (ACCORD COPD I). COPD. 2012; 9(2):90-101.

30. D'Urzo A, Kerwin E, Rennard S, He T, Gil EG, Caracta C. One-year extension study of ACCORD COPD I: safety and efficacy of two doses of twice-daily aclidinium bromide in patients with COPD. COPD. 2013; 10(4):500-510

31. Gelb AF, Tashkin DP, Make BJ, Zhong X, Garcia Gil E, Caracta C. Long-term safety and efficacy of twice-daily aclidinium bromide in patients with COPD. Respir Med. 2013;107(12):1957-1965.

32. Santus P, Radovanovic D, Di Marco F, Raccanelli R, Valenti V, Centanni S. Faster reduction in hyperinflation and improvement in lung ventilation inhomogeneity promoted by aclidinium compared to glycopyrronium in severe stable COPD patients. A randomized crossover study. Pulm Pharmacol Ther. 2015;35:42-49.

33. Scichilone N, Benfante A, Bocchino M, et al. Which factors affect the choice of the inhaler in chronic obstructive respiratory diseases? Pulm Pharmacol Ther. 2015;31:63-67.

34. Laube BL, Janssens HM, de Jongh FH, et al. What the pulmonary specialist should know about the new inhalation therapies. Eur Respir J. 2011;37(6):1308-1331.

35. Blasi F, Canonica GW, Centanni S, et al. Genuair ${ }^{\mathbb{R}}$ usability test: results of a National Public Survey of the Elderly. COPD. 2015;13(3):367-371.

36. Ismaila AS, Huisman EL, Punekar YS, Karabis A. Comparative efficacy of long-acting muscarinic antagonist monotherapies in COPD: a systematic review and network meta-analysis. Int J Chron Obstruct Pulmon Dis. 2015;10:2495-2517.

37. Fuhr R, Magnussen H, Sarem K, et al. Efficacy of aclidinium bromide 400 mug twice daily compared with placebo and tiotropium in patients with moderate to severe COPD. Chest. 2012;141(3):745-752.

38. Beier J, Kirsten AM, Mroz R, et al. Efficacy and safety of aclidinium bromide compared with placebo and tiotropium in patients with moderate-to-severe chronic obstructive pulmonary disease: results from a 6-week, randomized, controlled Phase IIIb study. COPD. 2013;10(4): $511-522$.

39. D’Urzo A, Ferguson GT, van Noord JA, et al. Efficacy and safety of once-daily NVA237 in patients with moderate-to-severe COPD: the GLOW1 trial. Respir Res. 2011;12:156.

40. Pleasants RA, Wang T, Gao J, Tang H, Donohue JF. Inhaled umeclidinium in COPD patients: a review and meta-analysis. Drugs. 2016;76(3): 343-361.

41. Mannino DM, Doherty DE, Sonia Buist A. Global Initiative on Obstructive Lung Disease (GOLD) classification of lung disease and mortality: findings from the Atherosclerosis Risk in Communities (ARIC) study. Respir Med. 2006;100(1):115-122.

42. Figarska SM, Boezen HM, Vonk JM. Dyspnea severity, changes in dyspnea status and mortality in the general population: the Vlagtwedde/ Vlaardingen study. Eur J Epidemiol. 2012;27(11):867-876.

43. Ni H, Soe Z, Moe S. Aclidinium bromide for stable chronic obstructive pulmonary disease. Cochrane Database Syst Rev. 2014;9:CD010509.
International Journal of COPD

\section{Publish your work in this journal}

The International Journal of COPD is an international, peer-reviewed journal of therapeutics and pharmacology focusing on concise rapid reporting of clinical studies and reviews in COPD. Special focus is given to the pathophysiological processes underlying the disease, intervention programs, patient focused education, and self management protocols.

\section{Dovepress}

This journal is indexed on PubMed Central, MedLine and CAS. The manuscript management system is completely online and includes a very quick and fair peer-review system, which is all easy to use. Visit http://www.dovepress.com/testimonials.php to read real quotes from published authors. 